\title{
A Clinical Study on the Treatment of Peripheral Nerve Injury Growth Factor of Mecobalamin Combined with Nerve
}

\author{
Chengkua Huang ${ }^{*}$, Guosheng Su${ }^{2 \#, ~ W e n ~ W e i ~}{ }^{1}$, Wenzhong Lu${ }^{1}$, Yinwen Mai ${ }^{1}$, \\ Shuliang Hua', Yong Zhao'1, Jili Lu' ${ }^{1}$ \\ ${ }^{1}$ The People's Hospital in Baise Guangxi, Youjiang Ethnic Southwest Hospital Affiliated to Medical School Spine \\ Surgery, Baise, China \\ ${ }^{2}$ The Fourth People's Hospital Clinical Laboratory Nanning Guangxi, Guangxi Medical University Affiliated to \\ Infectious Diseases Hospital of Nanning, Guangxi AIDS Clinical Treatment Center (Nanning), Nanning, China \\ Email: 1244943047@qq.com, "suguoshengv@sina.com, weiwenabcd@163.oom, Luwenzhong@163.com, \\ 13877685565@163.com, hsl8151@163.com,81840775@qq.com,024jili@163.com
}

Received 3 February 2016; accepted 20 March 2016; published 23 March 2016

Copyright (C) 2016 by authors and Scientific Research Publishing Inc.

This work is licensed under the Creative Commons Attribution International License (CC BY). http://creativecommons.org/licenses/by/4.0/

(c) (i) Open Access

\section{Abstract}

Objective: This research aims to explore the clinical curative effect for the treatment peripheral nerve injury growth factor of Mecobalamin combined with nerve. Methods: 150 cases of patients with peripheral nerve injury treated in the hospital in July were selected from 2011 to 2013. Those patients were randomly divided into three groups according to the types of injured nerve and the undergoing treatment order. 50 cases are for each group. Patients in group A were injected with $0.5 \mathrm{mg}$ Mecobalamin by intravenous injection. It lasted for once a day, for 10 days. Later, $0.5 \mathrm{mg}$ Mecobalamin was changed to be taken orally, three times a day, a course of treatment. And a course is 3 to 6 weeks. 50 patients in group B were injected with nerve growth factor for 30 micrograms by intramuscular injection, once a day, a course of treatment. And a course is 3 to 6 weeks. While in group $\mathrm{C}, 50$ patients were treated with Mecobalamin $(0.5 \mathrm{mg}$, intravenous injection, once a day) combined with nerve growth factor ( $30 \mathrm{mg}$, intramuscular injection, once a day). A course lasted 3 to 6 weeks. The purpose is to observe the therapeutic effect of two different drugs on patients with peripheral nerve injury. Results: The curative effect of Mecobalamin combined with nerve growth factors for the treatment of peripheral nerve injury in group $C$ is more significant than the single drug treatment in group A and group B. Peripheral nerve injury after sensorimotor function rating evaluation of curative effect made by The British Medical Research Institute of Neurotrauma Society was applied in this research. The comparison of the results of 3 groups after treatment is showed as follows. As to the sensory recovery above level II, the curative

\footnotetext{
*The first author.

\#Contribute equally as the first author and corresponding author.
}

How to cite this paper: Huang, C.K., Su, G.S., Wei, W., Lu, W.Z., Mai, Y.W., Hua, S.L., Zhao, Y. and Lu, J.L. (2016) A Clinical Study on the Treatment of Peripheral Nerve Injury Growth Factor of Mecobalamin Combined with Nerve. World Journal of Neuroscience, 6, 75-81. http://dx.doi.org/10.4236/wjns.2016.62009 
effect in $C$ group is generally better than in group $A$ and group $B$, the approximate chi square test $H$ $=13.6573, P=0.0011$. About motion recovery situation, there is a statistical significance in group $A$ and group $C$ which recovered $V$ level $X^{2}=3.8431, P=0.0499$, while there is no obvious difference in group $B(P>0.05)$. Conclusion: Some certain curative effect is presented of Mecobalamin combined with nerve growth factor in the treatment of peripheral nerve injury, which has an important clinical significance. Therefore, it is worth taking into application.

\section{Keywords}

Mecobalamin, Nerve Growth Factor, Peripheral Nerve Injury

\section{Introduction}

Peripheral nerve injury is the injury of the peripheral nerve trunk or its branches directly or indirectly affected by the external forces. At the present stage, peripheral nerve functional recovery after treatment still cannot achieve the ideal effect, especially patients with complete nerve injury. How to better promote the recovery of neural function, and ultimately improve the patient's life and work ability, so as to improve the quality of life are the need to solve the problem of clinician [1]-[3]. Peripheral nerve injury has always been a headache for clinical medical workers. After nerve anastomosis, it is a new task to improve the quality of end to side anastomosis after nerve anastomosis for the treatment of peripheral nerve defects. In order to find a way to treat the patients with peripheral nerve injury to achieve the best therapeutic effect, great efforts have been made in our hospital using comprehensive treatment measures in the clinical treatment of peripheral nerve injury. And satisfactory results have been achieved, which can be shown as follows.

\section{Materials and Methods}

\subsection{Objects of Study}

150 cases of patients with peripheral nerve injury treated in the hospital in July were selected from 2011 to 2013. All the patients were excluded from the injury before suffering from other nervous system diseases. Among them, 93 cases were male and 57 were female. The ages are ranging from 21 to 48 years old. Radial nerve injury contains 51 cases, including 3 cases of fractures caused by nerve rupture, 18 cases of partial rupture, 3 cases of completely cut injury, and 27 cases of incised wound. They were all found during operation. The median nerve injury are 72 cases, including 3 cases of fractures caused by nerve rupture, 24 cases of partial rupture, 3 cases of completely cut injury, 42 cases of partial cut injury in surgery exploration. There are 27 cases of ulnar nerve injury, including elbow fractures caused by complete rupture in 3 cases, partial nerve fracture in 6 cases, wrist cutting injury in 18 cases, of which completely cut injury in 3 cases, partial cut injury in 15 cases. They all were found during operation exploration. All selected patients were subject to the consent of their own and the consent of the medical management committee of our hospital. All patients were randomly divided into three groups according to the type of injured nerve and the order of the patients before and after treatment. Each group contains 50 cases. The patients in group A were 30 cases of male, 20 cases of female. Among them, radial nerve injury includes 18 cases, median nerve injury 24 cases, ulnar nerve injury 8 cases, including 5 cases of nerve completely broken. While in group B, patients are 31 cases of male and female 19, of which radial nerve injury is 17 cases, median nerve injury 23 cases, ulnar nerve injury 10 cases, of which are 7 cases of nerve completely broken. In group C, patients are 32 male, 18 female, of which radial nerve injury takes up 16 cases, median nerve injury 25 cases, ulnar nerve injury 9 cases. There are 6 cases of nerve completely broken. There was no significant difference between the three groups before and after treatment $(\mathrm{P}>0.05)$.

\subsection{Treatment Methods}

All patients were treated under a microscope tension-free end-to-end suture of epineurium during the day they got injured to the six days. After medication, the treatment of suture was carried out according to the design scheme of drug treatment. Patients in group A were injected with $0.5 \mathrm{mg}$ Mecobalamin by intravenous injection. 
It lasted for once a day, for 10 days. Later, $0.5 \mathrm{mg}$ Mecobalamin was changed to be taken orally, three times a day, a course of treatment. And a course is 3 to 6 weeks. 50 patients in group B were injected with nerve growth factor for 30 micrograms by intramuscular injection, once a day, a course of treatment. And a course is 3 to 6 weeks. While in group C, 50 patients were treated with Mecobalamin ( $0.5 \mathrm{mg}$, intravenous injection, once a day) combined with nerve growth factor (30 mg, intramuscular injection, once a day). A course lasted 3 to 6 weeks. The purpose is to observe the therapeutic effect of two different drugs on patients with peripheral nerve injury.

\subsection{Curative Effect Observation}

It aims to observe these two different usages of drugs on the treatment of patients with peripheral nerve injury. According to the injury site, this study used the British Medical Research Institute of neurology to develop the evaluation of sensory motor function after peripheral nerve injury. Specific assessment rules are as follows: feeling: grade 0 (S0) means feeling is no recovery. Grade I (S1) shows dominated areas of skin deep sensory feeling became recover, while grade II (S2) indicates dominated shallow tactile feeling and a part of it turned to recover. Grade III (S3) means pain and touch feeling of skin became recovering, and hypersensitivity disappeared. Grade IV (S4) reached the level of feeling and 2-PD recovered. Glass V (S5) indicated completely restored. Movement: Level 0 (M0) means muscle contraction. Level I (M1) indicated proximal muscles visible contraction. Level II (M2) means proximal and distal muscles were visible contraction. Level III (M3) indicated all important muscles can contract resistance. Level IV (M4) can do all the movement, including independent or cooperative movement. Level V (S5) is completely normal. Evaluation of the upper limb was assessed by the joint use of the Chinese medical association upper limb peripheral nerve function evaluation, while the lower limb were assessed by the joint use of Clawson-Seddon sciatic nerve injury evaluation criterion. Efficacy assessment level: S3M4 and above is optimal. S3M3 is for better. S2M2 is for good. S0-1M0-1 means the poor assessment level. Changes of sensory and motor function and electrophysiological were compared between the three groups after the treatment of 6 months. The efficiency is equal to the number of excellent cases plus good examples, then divided the sample content of this group. The cure rate is equal to the number of cases divided the sample content of this group.

\subsection{Statistical Treatments}

Statistical software of SPSS 17.0 was used to process statistics. Approximate chi square was used to show the comparison of three groups. If $\mathrm{P}$ is less than 0.05 , it will be considered to be statistically significant.

\section{Results}

\subsection{Comparison of the Results on the Treatment in the Three Groups}

After observing the patients in the three groups undergoing six months treatment, it is found that the curative effect of Mecobalamin combined with nerve growth factors for the treatment of peripheral nerve injury in group $\mathrm{C}$ is more significant than the single drug treatment in group A and group B. Peripheral nerve injury after sensorimotor function rating evaluation of curative effect made by The British Medical Research Institute of neurotrauma Society was applied in this research. The comparison of the results of 3 groups after treatment is showed as follow. As to the sensory recovery, the curative effect in $\mathrm{C}$ group is generally better than in group A and group $\mathrm{B}(\mathrm{P}<0.05)$. As for the recovery of movement, when it restored to $\mathrm{V}$ level, the differences were statistically significant $(P<0.05)$, while the rest has no too obvious differences $(P>0.05)$. Comparison of the results on before and after treatment, and recovery of sensory motor function between the 3 groups after the treatment will be showed in Table 1 and Table 2 .

\subsection{Recovery of Sensory after Treatment}

As to the recovery of sensory which reaches the level of I or above, the efficiency of treatment in group A and group $B, X^{2}$ equals $0.26(P<0.05)$, in group $A$ and group $C X^{2}=1.37,(P>0.05)$, while in group $B$ and group $C$, due to the little difference, it can't statistics. As for the recovery efficiency of treatment of sensory which reaches the level of II or above, comparing group A with group $\mathrm{B}, \mathrm{X}^{2}=0.54, \mathrm{P}>0.05$. Comparing with $\mathrm{A}$ and $\mathrm{C}, \mathrm{X}^{2}$ is equal to 4.76, $P<0.05$. Comparing with group $B$ and group $C, X^{2}$ is equal to 2.21 , $(P>0.05)$. As to the recovery efficiency of treatment of sensory which reaches the level of III or above, compared with the two groups 
Table 1. Hierarchical situation of sensation in three groups before and after treatment.

\begin{tabular}{|c|c|c|c|c|c|c|}
\hline Sensation & Level 0 & Level I & Level II & Level III & Level IV & Level V \\
\hline Before treatment in group A & 8 & 11 & 15 & 13 & 3 & 0 \\
\hline After treatment in group A & 3 & 9 & 18 & 11 & 8 & 2 \\
\hline $\begin{array}{l}\text { Comparison of before and } \\
\text { after treatment in group } \mathrm{A}\left(\mathrm{X}^{2}\right)\end{array}$ & 2.55 & 0.25 & 0.41 & 0.22 & 2.55 & 0.00 \\
\hline$P$ value & $>0.05$ & $>0.05$ & $>0.05$ & $>0.05$ & $>0.05$ & $>0.05$ \\
\hline Before treatment in group B & 7 & 10 & 16 & 14 & 3 & 0 \\
\hline After treatment in group B & 1 & 8 & 11 & 14 & 12 & 4 \\
\hline $\begin{array}{l}\text { Comparison of before and } \\
\text { after treatment in group } \mathrm{B}\left(\mathrm{X}^{2}\right)\end{array}$ & 3.40 & 0.27 & 1.27 & 0.00 & 6.35 & 2.34 \\
\hline$P$ value & $>0.05$ & $>0.05$ & $>0.05$ & $>0.05$ & $<0.05$ & $>0.05$ \\
\hline Before treatment in group C & 8 & 11 & 15 & 13 & 13 & 0 \\
\hline After treatment in group A & 0 & 4 & 6 & 14 & 16 & 10 \\
\hline $\begin{array}{l}\text { Comparison of before and } \\
\text { after treatment in group } C\left(\mathrm{X}^{2}\right)\end{array}$ & 6.66 & 3.84 & 4.88 & 0.05 & 0.44 & 11.11 \\
\hline$P$ value & $<0.01$ & 0.05 & $<0.05$ & $>0.05$ & $>0.05$ & $<0.01$ \\
\hline $\begin{array}{l}\text { Comparison of group A with B } \\
\text { after treatment }\left(\mathrm{X}^{2}\right)\end{array}$ & 0.26 & 0.07 & 2.38 & 0.48 & 1.00 & 0.18 \\
\hline$P$ value & $>0.05$ & $>0.05$ & $>0.05$ & $>0.05$ & $>0.05$ & $>0.05$ \\
\hline $\begin{array}{l}\text { Comparison of group A with } \mathrm{C} \\
\text { after treatment }\left(\mathrm{X}^{2}\right)\end{array}$ & 1.37 & 2.21 & 7.89 & 0.48 & 3.51 & 6.06 \\
\hline$P$ value & $>0.05$ & $>0.05$ & $<0.01$ & $>0.05$ & $>0.05$ & $<0.05$ \\
\hline $\begin{array}{l}\text { Comparison of group B with C } \\
\text { after treatment }\left(\mathrm{X}^{2}\right)\end{array}$ & - & 1.52 & 1.77 & 0.00 & 0.79 & 2.99 \\
\hline P value & - & $>0.05$ & $>0.05$ & $>0.05$ & $>0.05$ & $>0.05$ \\
\hline
\end{tabular}

A and $\mathrm{B}, \mathrm{X}^{2}$ is equal to $3.24, \mathrm{P}>0.05$. Comparing with group A with group $\mathrm{C}$, $\mathrm{X}^{2}$ equals $15.17, \mathrm{P}<0.01$, while compared with group A with group $C, X^{2}$ is equal to $4.76, P<0.05$. As to the recovery of sensory which reaches the level of IV or above, the efficiency of treatment in group $\mathrm{A}$ and group $\mathrm{B}, \mathrm{X}^{2}$ equals $\mathrm{X}^{2}$ equals $1.87, \mathrm{P}>0.05$, comparison in group $\mathrm{A}$ and group $\mathrm{C} \mathrm{X}^{2}$ is equals to 11.11, $\mathrm{P}<0.01$, while in group $\mathrm{B}$ and group $\mathrm{C}, \mathrm{X}^{2}$ equals 4.11, $\mathrm{P}<0.05$. Concerning with treatment efficiency of $\mathrm{V}$ level, comparing with group $\mathrm{A}$ and group $\mathrm{B}, \mathrm{X}^{2}$ equals $0.18(\mathrm{P}<0.05)$. Comparison in group $\mathrm{A}$ and group $\mathrm{C}$ is $\mathrm{X}^{2}=6.06, \mathrm{P}<0.05$, while group $\mathrm{B}$ and group $\mathrm{C}$ is $\mathrm{X}^{2}=2.99(\mathrm{P}>0.05)$.

\subsection{Motor Recovery after Treatment of the Three Groups}

As to treatment efficiency of motor recovery reaching level I or above, comparison of group A and group $\mathrm{B}, \mathrm{X}^{2}$ equals $0.4444, \mathrm{P}>0.05$. In group $\mathrm{A}$ and group $\mathrm{C}, \mathrm{X}^{2}$ is equal to $1.2228, \mathrm{P}>0.05$, group $\mathrm{B}$ and $\mathrm{C}$ group, $\mathrm{X} 2=$ $0.1773, \mathrm{P}>0.05$. About treatment efficiency of motor recovery reaching level II, comparison of group A and group $\mathrm{B}, \mathrm{X}^{2}$ equals $0.6378, \mathrm{P}>0.05$, in group $\mathrm{A}$ and group $\mathrm{C}, \mathrm{X}^{2}=1.1905, \mathrm{P}>0.05$, in $\mathrm{B}$ group and $\mathrm{C}$ group, $\mathrm{X}^{2}=0.0884, \mathrm{P}>0.05$. With regard to motor recovery efficiency of level III, comparing group A with group $\mathrm{B}$ $\mathrm{X}^{2}$ is equal to $0.00, \mathrm{P}>0.05$, group A with group $\mathrm{C}, \mathrm{X}^{2}=0.1984, \mathrm{P}>0.05$, group $\mathrm{B}$ with group $\mathrm{C}, \mathrm{X}^{2}=0.1984$, $\mathrm{P}>0.05$. As for motor recovery efficiency reaching IV level, comparing group $\mathrm{A}$ with group $\mathrm{B}, \mathrm{X}^{2}$ is equal to $0.7619, \mathrm{P}>0.05$. In group $\mathrm{A}$ and group $\mathrm{C}, \mathrm{X}^{2}$ equals $1.1688, \mathrm{P}>0.05$, group $\mathrm{B}$ and group $\mathrm{C}, \mathrm{X}^{2}=0.0440, \mathrm{P}>$ 0.05 . With regard to treatment efficiency of motor recovery, comparing group $\mathrm{A}$ with group $\mathrm{B}, \mathrm{X}^{2}$ equals 0.4444 $(\mathrm{P}<0.05)$. In group $\mathrm{A}$ and group $\mathrm{C}, \mathrm{X}^{2}$ is equal to 3.8431, $\mathrm{P}<0.05, \mathrm{~B}$ group and $\mathrm{C}$ group $\mathrm{X}^{2}=1.7718(\mathrm{P}>$ $0.05)$. 
Table 2. The comparison of strength grade of the three groups before and after treatment.

\begin{tabular}{|c|c|c|c|c|c|c|}
\hline Strength & Level 0 & Level I & Level II & Level III & Level IV & Level V \\
\hline Before treatment in group A & 14 & 11 & 12 & 10 & 3 & 0 \\
\hline After treatment in group A & 2 & 6 & 10 & 15 & 13 & 4 \\
\hline $\begin{array}{l}\text { Comparison of before and } \\
\text { after treatment in group } \mathrm{A}\left(\mathrm{X}^{2}\right)\end{array}$ & 10.71 & 1.77 & 0.23 & 1.33 & 7.44 & 2.34 \\
\hline$P$ value & $<0.01$ & $>0.05$ & $>0.05$ & $>0.05$ & $<0.01$ & $>0.05$ \\
\hline Before treatment in group B & 14 & 10 & 12 & 11 & 3 & 0 \\
\hline After treatment in group B & 1 & 4 & 7 & 15 & 17 & 6 \\
\hline $\begin{array}{l}\text { Comparison of before and } \\
\text { after treatment in group B }\left(\mathrm{X}^{2}\right)\end{array}$ & 13.25 & 2.99 & 1.62 & 0.83 & 12.25 & 4.43 \\
\hline P value & $<0.01$ & $>0.05$ & $>0.05$ & $>0.05$ & $<0.01$ & $<0.05$ \\
\hline Before treatment in group C & 14 & 11 & 12 & 10 & 3 & 0 \\
\hline After treatment in group C & 0 & 2 & 6 & 13 & 18 & 11 \\
\hline $\begin{array}{l}\text { Comparison of before and } \\
\text { after treatment in group } C\left(\mathrm{X}^{2}\right)\end{array}$ & 16.28 & 7.16 & 2.44 & 0.51 & 13.56 & 12.36 \\
\hline$P$ value & $<0.01$ & $<0.01$ & $>0.05$ & $>0.05$ & $<0.01$ & $<0.01$ \\
\hline $\begin{array}{l}\text { Comparison of group A with B } \\
\text { after treatment }\left(\mathrm{X}^{2}\right)\end{array}$ & 0.00 & 0.44 & 0.64 & 0.00 & 0.76 & 0.44 \\
\hline$P$ value & $>0.05$ & $>0.05$ & $>0.05$ & $>0.05$ & $>0.05$ & $>0.05$ \\
\hline $\begin{array}{l}\text { Comparison of group A with } \mathrm{C} \\
\text { after treatment }\left(\mathrm{X}^{2}\right)\end{array}$ & - & 1.22 & 1.19 & 0.2 & 1.17 & 3.84 \\
\hline$P$ value & - & $>0.05$ & $<0.01$ & $>0.05$ & $>0.05$ & 0.05 \\
\hline $\begin{array}{l}\text { Comparison of group B with } \mathrm{C} \\
\text { after treatment }\left(\mathrm{X}^{2}\right)\end{array}$ & - & 0.18 & 0.09 & 0.20 & 0.04 & 1.77 \\
\hline P value & - & $>0.05$ & $>0.05$ & $>0.05$ & $>0.05$ & $>0.05$ \\
\hline
\end{tabular}

\section{Discussion}

Nerve growth factor is also known as the Ganglioside (GM, N substance) which is a kind of composite glycolipids form by a hydrophilic group of sugar and a lipophilic lipid [4]. Glycosylation and Aliphatic distributes outside nerve cells and sets in the nerve cell substrate respectively. Nerve growth factor is a kind of natural ingredients of the cell membrane which can be used as effective drugs to promote the central nervous system (CNS) repair after injury. It may present in mammalian brain cells, especially in the central nervous system which is the most abundant [5]. The content of nerve growth factor can reflect the capacity of growth, repair and regeneration of peripheral nerve tissue. Nerve growth factor is natural ingredients of nerve cell membrane, which can complete the neural electric signals conduction and regulation of ion exchange, namely the regulation of potassium, sodium, calcium and other ions entering and existing cells. It can also stabilize the nerve cells and regenerate the peripheral nerve tissue after cell injury. At the same time, it is closely related to human being's memory and intelligence which can maintain the basic operation of the nervous system [6]. Damaging of peripheral nerve tissue can lead to a decrease in ganglioside content. If that happens, it should be promptly added enough supplement, in order to avoid the nerve cell membrane occurring the influx of calcium and calcium protein hydrolysis, which will eventually lead to the damage to the cell membrane and cause nerve cell apoptosis and the destruction of the cell membrane function, which makes the dying nerve cell loss of physiological function. It is not conducive to neural network remodeling of the acute brain injury such as stroke.

Methylcobalamin is involved in the cycle of one unit of carbon. It is a kind of endogenous vitamin B12, which plays a significant role in the reaction process of methionine synthesis [7]-[10]. And Mecobalamin easily enters into neuronal organelles and participates in the synthesis of thymidine, as well as promote the synthesis of 
protein, enhances the use of folic acid and the metabolism of nucleic acid. Secondly, Mecobalamin can promote regeneration of axons and axonal transport function, and suppress nerve degeneration caused by drugs. Mecobalamin can promote formation of neuronal myelination and synthesis of lecithin, so that the occurrence of delayed neural synaptic can better transmit, and reduce neurotransmitter back to be normal. Meanwhile, increasing the excitability of nerve fibers can restore the endplate potentials and induction, and makes the brain acetylcholine return to the normal level [11]-[13]. Chen Feng [3] and other scholars have carried out some researches which showed that the two kinds of combination of drugs have a synergistic effect.

The results of the study show that the curative effect of Mecobalamin combined with nerve growth factors for the treatment of peripheral nerve injury is more significant. Comparing with the single drug treatment, the total effective rate of sensory and motor recovery before and after the treatment was statistically significant different $(\mathrm{P}<0.05)$. Peripheral nerve injury after sensorimotor function rating evaluation of curative effect made by The British Medical Research Institute of neurotrauma Society was applied in this research. The comparison of the results of 3 groups after treatment, as to the sensory recovery, the curative effect of combination of drugs is generally better than the single drug treatment of Mecobalamin or nerve growth factors $(\mathrm{P}<0.05)$. About motion recovery situation, there is statistical significance in groups which recovered $\mathrm{V}$ level, while there is no obvious difference in group $\mathrm{B}(\mathrm{P}>0.05)$.

\section{Conclusion}

If Mecobalamin can be used to combine with nerve growth factor in the treatment of peripheral nerve injury, it will have a statistical significance. Compared with the single drugs treatment, there is an obvious statistical difference of sensory and motor recovery before and after the treatment when drugs can be used jointly $\mathrm{P}<0.05$, which can provide better clinical methods in treating injury of brain tissue and has an important clinical significance. However, though some achievement has been reached in this study, because of some limitation, it still needs further long-term observation.

\section{Limitations of the Study}

Some limitations exist in the research, such as relatively short time in the study few selected cases of patients, and some patients unwilling to return to the hospital to reexamine again. Meanwhile, because of the limited funding, the number of selected cases is not enough to attain the representative research results. Therefore, we strongly hope to have more research funding, in order to make the research results more representative.

\section{Acknowledgements}

During this topic research process, we got help from many departments and individuals, such as the projects of science and technology, and other personnel not involved in this project research, all of them offered a great support and help in this research. Now here, all of members of this research group show our deepest appreciation to them, and wish them good health and everything goes well.

\section{Fund Project}

Guangxi Baise science and technology plan projects of the People’s Republic of China (No.: 20111209).

\section{References}

[1] Chen, W.J. (2015) A Clinical Observation on the Treatment of Diabetic Peripheral Neuropathy by Su Taisheng Combined with Safflower Yellow. Modern Diagnosis and Treatment, 17, 768-769.

[2] Pan, H.Y. (2015) A Study on the Influence of Effects of Nerve Growth Factor on Nerve Conduction Velocity and AR, NO and SOD in Patients with Diabetic Peripheral Neuropathy. Modern Medical, 15, 51-52.

[3] Chen, F. and Xu, E.D. (2014) Observation on the Treatment of Elderly Diabetes Peripheral Neuropathy with Nerve Growth Factor Combined with Mecobalamin. Modern Clinical Medicine, 40, 411-413.

[4] Vizza, D., Perri, A., Lofaro, D., et al. (2013) Exposure to Nerve Growth Factor Worsens Nephrotoxic Effect Induced by Cyclosporine A in HK-2 Cells. PLoS ONE, 8, e80113. http://dx.doi.org/10.1371/journal.pone.0080113

[5] Acosta, C.M., Cortes, C., MacPhee, H., et al. (2013) Exploring the Role of Nerve Growth Factor in Multiple Sclerosis: 
Implications in Myelin Repair. CNS \& Neurological Disorders-Drug Targets, 12, 1242-1256. http://dx.doi.org/10.2174/18715273113129990087

[6] de Souza Aarão, T.L., Esteves, N.R., Esteves, N., de Miranda Soares, L.P., da Silva Pinto, D., Fuzii, H.T. and Quaresma, J.A.S. (2014) Relationship between Growth Factors and Its Implication in the Pathogenesis of Leprosy. Microbial Pathogenesis, 77, 66-72. http://dx.doi.org/10.1016/j.micpath.2014.10.005

[7] Gan, L., Qian, M.Q., Shi, K.Q., et al. (2014) Restorative Effect and Mechanism of Mecobalamin on Sciatic Nerve Crush Injury in Mice. Neural Regeneration Research, 22, 1979-1984. http://dx.doi.org/10.4103/1673-5374.145379

[8] Mizukami, H., Ogasawara, S., Yamagishi, S., et al. (2011) Methylcobalamin Effects on Diabetic Neuropathy and Nerve Protein Kinase C in Rats. European Journal of Clinical Investigation, 41, 442-450. http://dx.doi.org/10.1111/j.1365-2362.2010.02430.x

[9] Li, J.-B., Wang, C.-Y., Chen, J.-W., et al. (2010) The Preventive Efficacy of Methylcobalamin on Rat Peripheral Neuropathy Influenced by Diabetes via Neural IGF-1 Levels. Nutritional Neuroscience, 13, 79-86. http://dx.doi.org/10.1179/147683010X12611460763607

[10] Tanaka, H. (2013) Old or New Medicine? Vitamin B12 and Peripheral Nerve Neuropathy. Brain Nerve, 65, 10771082.

[11] Xu, Q., Pan, J., Yu, J., et al. (2013) Meta-Analysis of Methylcobalamin Alone and in Combination with Lipoic Acid in Patients with Diabetic Peripheral Neuropathy. Diabetes Research and Clinical Practice, 101, 99-105. http://dx.doi.org/10.1016/j.diabres.2013.03.033

[12] Han, W., Hu, S., et al. (2013) Methylcobalamin: A Potential Vitamin of Pain Killer. Neural Plasticity, 42, 651.

[13] Calcutt, N.A. (2010) Tolerating Diabetes: An Alternative Therapeutic Approach for Diabetic Neuropathy. ASN Neuro, 2, e00042. http://dx.doi.org/10.1042/an20100026 